Article

\title{
Geospatial Analysis of Photovoltaic Mini-Grid System Performance
}

\author{
Thomas Huld ${ }^{1, *}$, Magda Moner-Girona ${ }^{1}$ and Akos Kriston ${ }^{2}$ \\ 1 European Commission, Joint Research Centre, Via Fermi 2749, I-21027 Ispra, Italy; magdamnr@gmail.com \\ 2 European Commission, Joint Research Centre, Westerduinweg 3, NL-1755 ZG Petten, The Netherlands; \\ akos.kriston@ec.europa.eu \\ * Correspondence: thomas.huld@jrc.ec.europa.eu; Tel.: +39-0332-785-273; Fax: +39-0332-789-268
}

Academic Editor: Senthilarasu Sundaram

Received: 2 December 2016; Accepted: 2 February 2017; Published: 15 February 2017

\begin{abstract}
We present a geographic information system (GIS)-based tool for estimating the performance of photovoltaic (PV) mini-grid system over large geographical areas. The methodology consists of geospatial analysis and mapping of the energy output and reliability of PV mini-grid system. The algorithm uses a combination of hourly solar radiation data from satellites combined with measured data on PV module and battery performance and estimated electricity consumption data. The methods also make it possible to optimize the PV array and battery storage size for a given location. Results are presented for an area covering Africa and most of Southern and Central Asia. We also investigate the effects of using Li-ion batteries instead of the traditional lead-acid batteries. The use of our spatial analysis as decision support tool could help governments, local authorities and non-governmental organizations to investigate the suitability of PV mini-grids for electrification of regions where access to electricity is lacking. In this way it is possible to identify areas where PV mini-grids are most suitable.
\end{abstract}

Keywords: photovoltaic (PV) performance; mini-grid systems; battery storage

\section{Introduction}

\subsection{Motivation}

Modern energy services are crucial to human well-being and to a country's economic development; and yet 1.2 billion people (17\% of the global population) are without access to electricity [1]. More than $95 \%$ of those living without electricity are in countries in sub-Saharan Africa and developing Asia, predominantly in rural areas [2-4]. In recognition of these facts, the United Nations Secretary General launched in 2012 the Sustainable Energy for All (SE4All) Initiative with an overarching objective of ensuring universal access to sustainable energy by 2030 [5,6].

Additionally, it is recognized that the central grid is unlikely to reach many remote areas in the near future: many of these communities will have low electricity consumption, making the costs of extending the grid unaffordable [7]. The RE2NAF rural electrification tool [8], based on our previous studies $[9,10]$, estimates that grid extension will be the least-cost option for around $40 \%$ of the population, and stand-alone and mini-grid systems will be the least-cost option to deliver electricity to $60 \%$ of the African population.

The motivation of this study originates from the evident potential of solar energy for African and South East Asia countries and the prospect of using distributed photovoltaic (PV) systems as an alternative approach to meet the objective of universal electrification $[3,11,12]$. Our previous studies already indicate that PV mini-grids are a viable solution to provide high quality access to electricity in Africa $[9,10]$ and the same indications can be found in a very similar study [13]. Detailed rural 
electrification studies have provided helpful insights at national level [14-18]. The focus of this paper is to provide a geospatial analysis of the performance of PV mini-grids in Africa and South East Asia regions giving special attention to the energy storage effects.

The electricity consumption loads in this study are related to the SE4All multi-tier access demand scenario $[19,20]$, that better captures the quantity and quality of electricity supplied, such as the duration of availability of electricity per day. For consistency, the PV mini-grid have been designed to deliver a $24 \mathrm{~h}$ electricity services under a Tier 3 level of access to electricity supply [5]. There exist a number of well-known models for the optimization of RES hybrid systems at local level [21-23]. The novelty of our approach is the combination of geospatial analysis with PV mini-grid optimization modeling at continental level to accurately assess both the solar resource but also how well it balances with the battery storage. Our approach differs from previous studies in terms of the long time-series simulation and spatial accuracy introduced in the analyses. We analyse the PV mini-grid performance by a 1-h time scale over a whole year for each 6 arc-minutes (approx. $10 \mathrm{~km}$ ) of the geographical extension under study.

\subsection{Energy Storage: Lead-Acid and Li-ion Batteries}

Energy storage is inherently valuable in distributed energy systems and they have been widely used for off-grid applications. Lead-acid batteries are on the market for more than a 100 years. Even though several variances have been introduced during the decades such as valve-regulated lead acid (VRLA), starter or deep cycle battery their basic chemistry of energy storage is the same.

Li-ion batteries are much younger, commercialised in the 1990's [24]. Li-ion battery generally means that Li-ion shuttles between the negative and positive storage materials and intercalets into a host material [25]. More recently, a cheaper cathode material containing abundant elements such as Lithium Iron Phosphate (LFP) has been developed and introduced to the market from the beginning of the 2000's [26]. Compared to other Li-ion technologies this has longer cycle life (3000-5000 cycles) and higher tolerance for overheating. The primary application of LFP batteries is energy storage, since it has a relatively low energy density of $100-180 \mathrm{Wh} \cdot \mathrm{kg}^{-1}$ compared to Li-ion technologies used for automotive applications. Even though their price is still higher than that of lead-acid batteries, their longer service life (3000-5000 cycles instead of 700-1500 for lead-acid), higher power (1-2 C-rate instead of 0.3-0.5 C-rate for lead acid) make them competitive in new applications, such as mini-grids in rural areas.

The overall price of Li-ion based energy storage systems have decreased considerably recently and is projected to reach $€ 90 / \mathrm{kWh}$ by $2030[27,28]$. Tesla offers a range of product starting from around $€ 5000$ (+installation) for $14 \mathrm{kWh}$ storage, a very competitive price compared to other Li-ion based technologies. Cheaper solutions are expected by reusing aged automotive traction batteries, such as Nissan or BMW have suggested. While the energy density of an aged battery is not suitable for vehicle they still have the $80 \%$ of the capacity, which can be used for energy storage application with less demanding power requirements. A new feature in our spatial analysis tool is the introduction of the effect of Li-ion batteries as an alternative to lead-acid batteries on the performance of PV mini-grids.

\subsection{Specific Aims and Structure of the Paper}

Our main research questions when conducting geospatial analysis of the PV mini-grid performance at continental level are:

(i) What is the geographical variation of the PV mini-grid energy production and performance under current technology costs for both PV mini-grids of a given size?

(ii) What is the geographical variation of the PV mini-grid energy production and performance for optimally sized PV mini-grids?

(iii) What is the variability of unfulfilled demand depending on geographical location?

(iv) How many days will the PV mini-grid suffer power interruptions due to empty batteries? 
(v) What is the influence of the choice of Li-ion over lead-acid batteries on the costs and overall performance of the PV mini-grid?

(vi) For each location, how much energy is not used if battery becomes full and the PV power exceeds consumption?

(vii) For each location, what is the optimum size of batteries that will ensure delivery of the desired daily energy consumption below a given power failure threshold?

To address the above issues the paper is organized as follows: Section 2 presents the mathematical models and source of input data used to calculate the power outut produced by the PV mini-grids. Section 3 presents a number of simulation results, both for PV mini-grid systems of given size and for optimally sized PV mini-grid systems. We discuss the geographical aspects of the variability in PV mini-grid performance, including the geospatial analysis and mapping of the main research questions. Section 3.2 focuses on answering questions (i) and (ii), the spatial analysis of PV mini-grid performance and power interruptions. Section 2.5 attempts to answer questions (iii), (iv) and (v), the mapping of the optimization of PV mini-grid, balance between PV generator and battery capacities, and the analysis of the lead-acid or Li-ion batteries. Finally, our conclusions are stated in Section 4.

\section{Models}

The methods applied here for estimating the energy production of PV mini-grid systems use the combination of several models (see Figure 1): a model for effective irradiance (Section 2.1) -with solar radiation measured from satellites-, a PV output power model (Section 2.2) -with measured data on module performance-, and a model for battery performance (Section 2.3)—based on measured battery data.

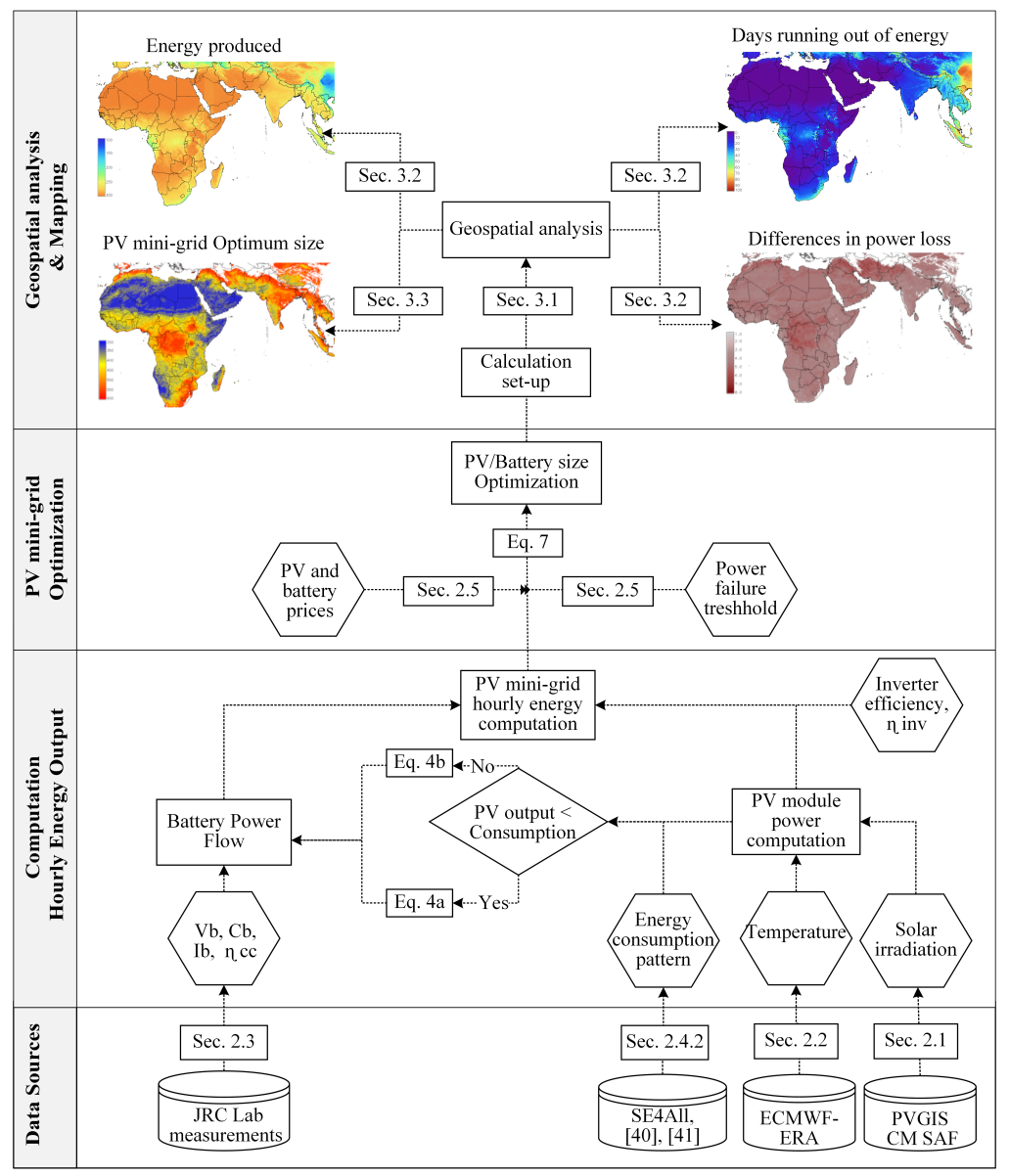

Figure 1. Flowchart diagram of the models employed for this study. 


\subsection{In-Plane Solar Irradiance}

The solar radiation data used for this study consist of hourly values of global horizontal and direct horizontal irradiance. Since PV arrays are typically mounted at an angle from horizontal it becomes necessary to calculate the solar irradiance in the plane of the PV modules. Here we have applied the model of Muneer [29], see also Šúri and Hofierka [30].

The surface reflectivity of PV modules depends on the incident angle of the light, which in turn depends on the module inclination, the position of the sun, and on how much of the incoming sunlight consists of diffuse light. To account for this effect we employ the model of Martin and Ruiz [31].

Applying these two models we obtain the effective irradiance, i.e., the solar irradiance that is available to produce power at any given instant.

Input: Solar Radiation Data

Hourly solar radiation values have been obtained from satellite data. The methods used to estimate ground-level solar irradiance from satellite data are described in Müller et al. [32] and Posselt et al. [33].

The solar radiation data consist of values for the global horizontal and direct horizontal irradiance whereby it is possible to calculate the solar irradiance on inclined planes.

The time resolution of the solar radiation data is hourly, while the spatial resolution is 3 arc-minutes (about $5 \mathrm{~km}$ ). For Europe and Africa the data are available from the CM SAF Collaboration (www.cmsaf.eu). The data for Asia have been calculated using the same methods and have recently been made available from the same site [34].

\subsection{Model for Instantaneous Output Power of the PV Modules}

Instantaneous PV output power, $P_{h}$, is calculated using the model described in Huld et al., 2011 [35]. In this model, the instantaneous PV power is an explicit function of in-plane irradiance and module temperature. The coefficients used for modelling crystalline silicon (c-Si) PV modules are also taken from [35]. The module temperature $T_{\text {mod }}$ has been calculated from air temperature $T_{\mathrm{amb}}$ and in-plane irradiance $G_{i}$ using the following simple model:

$$
T_{\text {mod }}=T_{\mathrm{amb}}+0.035 \cdot G_{i}
$$

This corresponds to a nominal operating cell temperature (NOCT) of $48{ }^{\circ} \mathrm{C}$. The model does not take into account the effects of wind cooling the PV modules. Cooling by wind may cause an increase in PV energy production varying by about $0-7 \%$ depending on the local wind strength [36].

In the present study we have used only data for crystalline silicon modules. However, there is no reason why other types of modules can not be modelled as well. The above model has also been applied to CuInSe ${ }_{2}$ and CdTe module technologies [37].

The effects of spectral variations have not been considered in this study, mainly because of the large increase in computational effort that would be necessary. Recent results [38] suggest that at least for c-Si PV modules this effect is not very large in most of the chosen study area.

The effects of dust deposition on the PV energy output has not been considered, as there are not sufficient data to determine the geographical variation in this effect. Thus, it is implicitly assumed that the PV arrays will be cleaned when necessary.

The resulting PV power values are the DC power delivered to the inverter, assuming maximum power point tracking.

\section{Input: Air Temperature Data}

For the present study air temperature data have been taken from the ECMWF ERA-interim reanalysis data [39] (www.ecmwf.int). The temporal resolution of the data is 3-hourly while the spatial resolution is 45 arc-minutes (about $80 \mathrm{~km}$ ). The fairly coarse resolution may cause the PV performance 
calculations to be less accurate in areas with large elevation variations due to the temperature change with altitude.

In order to produce an hourly time series of temperature data, the 3-hourly data are interpolated linearly to estimate hourly temperature values.

\subsection{Model for the Battery Charge/Discharge Cycle}

The state of charge of a battery, SOC, is an important parameter which influences the battery performance. It is described as the percentage of the total battery capacity that is still available to discharge. This is loosely analogous to an automobiles' fuel tank: $0 \%$ indicates an empty tank and $100 \%$ indicates a full tank (International Electrotechnical Commission Standards IEC 61960, IEC 62133, and IEC 62660). When a battery is charged or discharged, the voltage across the terminals of the battery will depend on the current into or out of the battery $\left(I_{b}\right)$, as well as on the SOC. The battery voltage, $V_{b}$, is thus written as:

$$
V_{b}=V_{b}\left(I_{b}, \mathrm{SOC}\right)
$$

The dependence of $V_{b}$ on $I_{b}$ and SOC has been measured experimentally for a number of different values of SOC and $I_{b}$ for each of the battery technologies used for this study. From these measurements the function $V_{b}$ is then defined as a matrix of discrete values, from which the value of $V_{b}$ can be found for any set of values SOC and $I_{b}$ by interpolation (or for extreme cases extrapolation).

Another way to express the charge/discharge current is the C-rate, which is the inverse of the time (in hours) it takes to go from fully discharged to fully charged (or vice versa).

\subsubsection{Input Data: Battery Performance Data for Lead-Acid Batteries}

Data for lead-acid batteries were performed on a Ritar DG-12-120 deep-cycle GEL battery (nominally $12 \mathrm{~V}$ and 120 Ah capacity), which is currently used for solar applications. The temperature during the measurements was not explicitly controlled but was always within the interval $23-25^{\circ} \mathrm{C}$. For both charging and discharging the current into the battery was controlled by a KEPCO programmable power supply. A STECA charge controller was connected between battery and power supply to avoid excessive charge or discharge. Voltage, current and temperature data were recorded at 1-min intervals using an Agilent 34970A data logger (Agilent Inc., Santa Clara, CA, USA) Charge/discharge cycles were performed to obtain a matrix of battery voltage as a function of current (or C-rate) and SOC.

For the lead-acid charge/discharge cycle the C-rate did not exceed 0.2, corresponding to $5 \mathrm{~h}$ to fully charge or discharge the battery. For realistic mini-grid operations this is not a significant restriction since $\mathrm{C}$-rates are nearly always lower than this.

Figure 2 shows the charge/discharge voltage as a function of the C-rate and SOC.

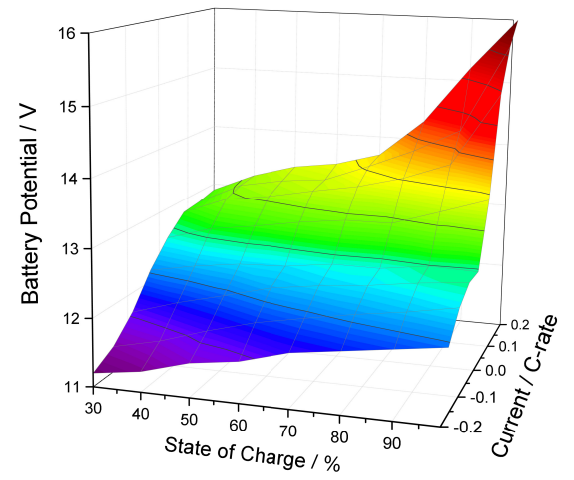

Figure 2. Lead-acid battery charge/discharge voltage as a function of the current (expressed as the C-rate) and state of charge (SOC). 


\subsubsection{Input Data: Performance Data for Li-ion Batteries}

Cycling data of a LFP 40 Ah Li-ion battery cell from CALB Corporation (Luoyang, China) has been used for the calculation of mini-grid performance with Li-ion batteries. The selected cell is designed for energy storage application, therefore it is supposed to be representative for the mini-grid application. The battery was placed in a temperature chamber (Vötsch Industrietechnik, Stuttgart, Germany) and cycled by a Maccor cycler (Tulsa, OK, USA) between 2.5 and $3.65 \mathrm{~V}$ at an ambient temperature of $30{ }^{\circ} \mathrm{C}$, which represents the full SOC window. The discharge, charge current was altered from $0.1 \mathrm{C}$-rate $(4 \mathrm{~A})$ to $0.7 \mathrm{C}$-rate $(28 \mathrm{~A})$ and the potential and the cumulative charge have been recorded. State of charge (SOC) was calculated by normalizing the cumulative charge by the rated capacity (40 Ah). Figure 3a shows the measured cell potential at different current densities (C-rate) as a function of the cumulative charge, which corresponds to the manufacturer's data and to other LFP batteries [26]. The curves shows that at the end and at the beginning of the charge and discharge the potential varies (increase or decrease) steeply which deteriorates the round-trip efficiency. Therefore a lower SOC window is applied. The narrower SOC window also implies longer cycle life. According to the manufacturer the expected service life is 5000 cycles and 10 years. The battery pack potential in Figure $3 \mathrm{~b}$ has been extrapolated to a serial connection of 4 identical cells (multiplying the measured cell potential by 4 ) to reach a more realistic use case scenario. In the selected SOC and current rate window the potential (i.e., efficiency) varies in a much narrower range compared to a lead-acid battery and it is also less dependent on the current rate below $0.7 \mathrm{C}$. This better performance may originate from the lower internal resistance and the higher than 99\% Coulombic efficiency.

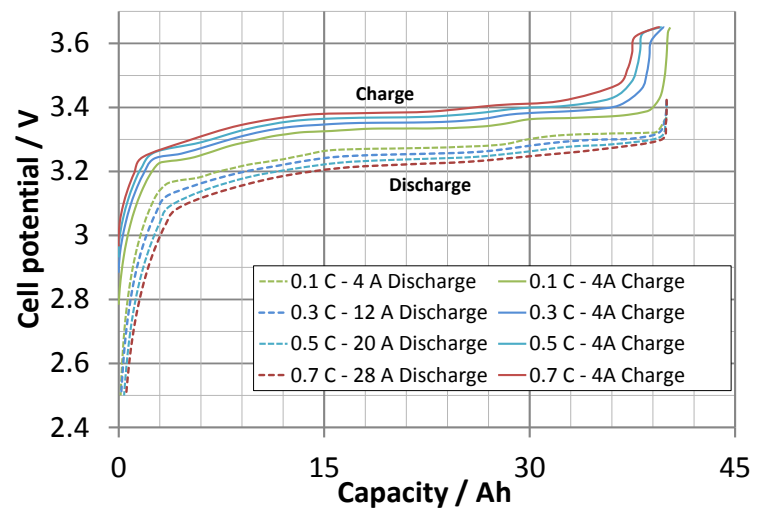

(a)

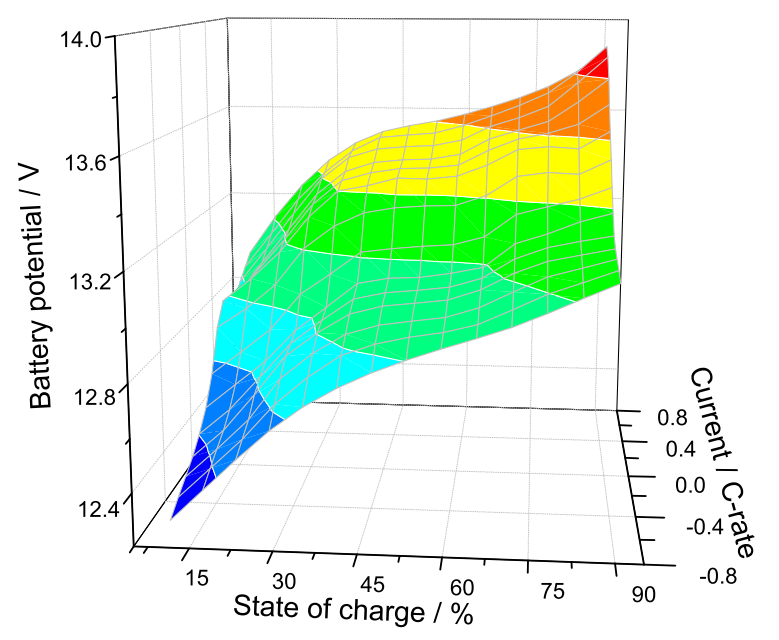

(b)

Figure 3. The Lithium Iron Phosphate (LFP) Li-ion battery characteristics (a) measured charge and discharge curves (b) extrapolated data to a $12 \mathrm{~V}$ battery pack.

\subsection{Model for Energy Produced by the PV Mini-Grid System with Battery Storage}

The energy production of a PV mini-grid -consisting of PV and battery arrays and inverters- is calculated by using a combination of the models described in Sections 2.1, 2.2 and 2.3 for a specific pattern of electricity consumption (Section 2.4.2).

\subsubsection{Model for PV-Battery System Performance}

Time resolution of the climatic data is hourly, so the time step of the system simulation will be $1 \mathrm{~h}$. The algorithm consists of the following steps: 
Using the solar radiation and temperature data together with the models in Sections 2.1 and 2.2 calculate the PV power. The energy produced by the PV system in hour $h$ is then:

$$
E_{P V, h}=P_{h} *\left(1-\eta_{\text {inv }}\right)
$$

Here, $\eta_{\text {inv }}$ is the DC/AC inverter efficiency.

The energy going into the battery, $E_{b, h}$, taking into account the inverter loss both in charging and discharging the battery, is given by:

$$
E_{b, h}= \begin{cases}E_{P V, h}\left(1-\eta_{\mathrm{cc}}\right)-E_{c, h} & E_{P V, h}>E_{c, h} \\ E_{P V, h}-E_{c, h} /\left(1-\eta_{\mathrm{cc}}\right) & E_{P V, h}<E_{c, h}\end{cases}
$$

Here $\eta_{\mathrm{cc}}$ is the efficiency of the battery charge/discharge inverter and $E_{c, h}$ is the energy consumption at hour $h$.

The hourly $\mathrm{SOC}, \mathrm{SOC}_{h}$, changes by:

$$
\Delta \mathrm{SOC}=E_{b} / V\left(I_{b, h}, \mathrm{SOC}_{h}\right)
$$

If $\mathrm{SOC}_{h}$ drops below the charge cut-off for the battery, the energy delivered to the customers during the hour is reduced correspondingly. Conversely, if $\mathrm{SOC}_{h}$ reaches maximum battery capacity, the flow of current into the battery is interrupted.

If the power delivered to the battery, $P_{b}$, is assumed to be constant during the hour interval, the power can be written as:

$$
P_{b}=E_{b} / t=I_{b} \cdot V\left(I_{b, h}, \mathrm{SOC}_{h}\right)
$$

$E_{b}$ is known from Equation (4), but $I_{b}$ must be determined. This is done using a matrix of battery voltage values for different battery currents and charge states, as described in Sections 2.3.1 and 2.3.2. For each current value in the matrix, the voltage for the present charge state is found by linear interpolation between values in the matrix. Then the $(V, I)$ pairs are fitted to a fifth-order polynomial $V\left(I_{b}, \mathrm{SOC}\right)$. The result is that Equation (6) becomes a sixth-order polynomial equation in $I_{b}$, which is then solved by an iterative Newton-Raphson algorithm. Once $I_{b}$ is known the SOC can be calculated for the next hour.

The models for power output from the PV generator and battery state given above have been implemented in GIS software as a module in the open-source GRASS GIS. The calculation uses hourly time series of solar irradiance and air temperature together with data on PV module and battery performance. For each hour during the selected time period the model calculates:

- $\quad$ Energy produced

- $\quad$ Battery state of charge (SOC)

- $\quad$ Energy missing if battery becomes empty

- Energy not used if battery becomes full and the PV power exceeds consumption

- Number of days when power fails due to empty battery

The calculation is performed at hourly intervals for an extended time period. The final output consists of the yearly totals of the values in this list.

\subsubsection{Input Data: Energy Consumption Profiles}

For the present study, two different electricity consumption loads have been designed to deliver a $24 \mathrm{~h}$ electricity services under levels of access to electricity supply based on the SE4All multi-tier matrix. One daily consumption profile is based on a low energy consumption pattern of $<1 \mathrm{kWh} /$ day per household (Tier 2) with most of the consumption taking place during evening [40]. With this consumption profile, $2 / 3$ of the energy consumption takes place between sunset and sunrise. In the following, this will be termed the "high nighttime consumption" case. 
The other profile used represents a consumption pattern with higher consumption per household (Tier 3) of $2.2 \mathrm{kWh} /$ day [41]. This case assumes the use of medium-power appliances with about 2/3 of the energy consumed during daytime. In the following, this will be termed the "low nighttime consumption" case. The two consumption curves are shown in Figure 4.

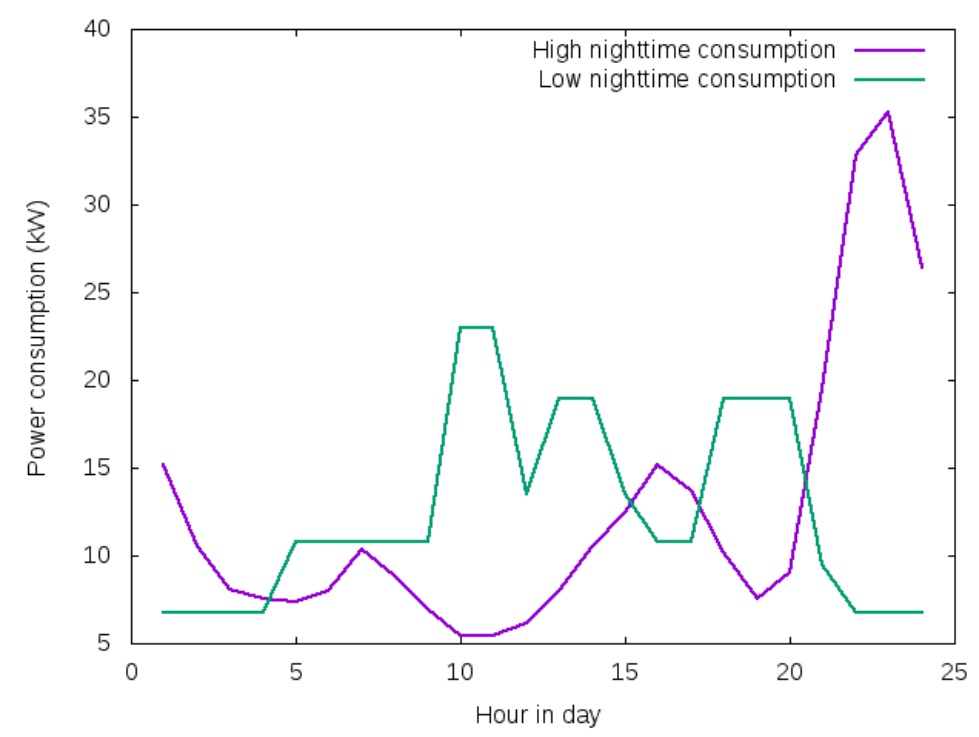

Figure 4. Daily consumption profiles, given as hourly values of the instantaneous consumption, in $\mathrm{kW}$. Both consumption patterns are scaled to an overall daily electricity consumption of $300 \mathrm{kWh}$.

The consumption curves are assumed to repeat in the same way every day. For a large number of consumers this will generally be a good assumption unless external factors affect the consumption, for instance if seasonal effects make the consumption vary over the year. This could well be the case in the most northerly parts of the study area where lighting would be more needed in winter. Another simplifying assumption is that consumption will not be deferred: if the system runs out of power for a time period the electricity needs during that time will not be met at a later time. For some applications such as lighting and televisions this is a good approximation but for other loads, such as refrigerators, lost power at one point will tend to be compensated by greater consumption later on. At the moment we do not have sufficient details about the type of electricity consumption to take this effect into account.

The calculation domain spans more than $120^{\circ}$ in longitude corresponding to approximately 8 time zones. The solar radiation and temperature data have time stamps in Universal time (UTC), but it would not be correct to assume that the same consumption profile in UTC would be appropriate everywhere. For this reason the consumption data are shifted by one hour for each $15^{\circ}$ longitude. This may cause small discontinuities in the calculated outputs at the boundaries where the consumption profiles shifts by one hour.

\subsection{Calculation of Optimum PV Mini-Grid Size}

Both the total amount of solar irradiation and the intermittency of the solar irradiance depend strongly on location. For this reason the same PV/battery combination may be overdimensioned for some locations and undersized in other places. It would therefore be useful to perform an optimization to find the best combination of PV array and battery storage size. Of course, the "best" system depends on the what criteria are deemed most important, whether it be power production reliability, installation cost or some other criterion. For this study we have adopted the following criterion: Determine the least-cost combination of $P V$ array and battery that will ensure delivery of the desired daily energy consumption with probability of power failures below a given threshold. In other words, if we wish to deliver 
a certain amount of energy daily and have power failure on less than $X \%$ of days, what is the least-cost combination of PV array and battery?

The PV/battery system cost $K_{\text {syst }}$ is calculated as:

$$
K_{\text {syst }}=K_{\mathrm{PV}} P_{\text {nom, }, \mathrm{PV}}+K_{\mathrm{bat}} C_{\text {nom,bat }}
$$

Here $K_{\mathrm{PV}}$ is the price of the PV system per $\mathrm{kWp}$ and $P_{\mathrm{nom}, \mathrm{PV}}$ is the size of the PV array in $\mathrm{kWp}$. $K_{\text {bat }}$ is the price of the battery per kWh of nominal capacity and $C_{\text {nom,bat }}$ is the nominal capacity of the battery. The cost of the balance-of-system components is presumed to be proportional to the size of the PV array.

The optimization calculation is done in the following steps:

- For a range of $\left(N_{\mathrm{PV}}\right) \mathrm{PV}$ array and $\left(N_{\text {bat }}\right)$ battery sizes, calculate the energy performance for the selected time period using all $N_{\mathrm{PV}} \times N_{\text {bat }}$ combinations,

- For all PV/battery combinations find the combination that has power failure probability below the threshold and has the least cost according to Equation (7).

The optimization is based on the lowest PV mini-grid cost, taking into account also the need for replacement of the batteries. The assumptions for the cost are the following:

- $\quad$ PV module cost $830 € / \mathrm{kW}_{\mathrm{p}}$

- $\quad$ PV balance-of-system cost $1000 € / \mathrm{kW}_{\mathrm{p}}$

- $\quad$ PV system lifetime 20 years

- $\quad$ Lead-acid battery cost $122 € / \mathrm{kWh}$ nominal

- $\quad$ Lead-acid battery lifetime 5 years

- $\quad$ Li-ion battery cost $350 € / \mathrm{kWh}$ nominal

- Li-ion battery lifetime 10 years

Future replacements are discounted at $5 \%$ /year. This means that the effective cost of 4 lead-acid battery sets is 2.83 times the cost of one battery set while the effective cost of $2 \mathrm{Li}$-ion battery sets is 1.60 times the cost of one battery set. The total cost $K$ of a mini-grid with PV array size $P_{\mathrm{PV}}$, and battery size $C_{\text {bat }}$, is then:

$$
\begin{array}{ll}
K=1830 \times P_{\mathrm{PV}}+2.67 \times 122 \times C_{\text {bat }}, & \text { for } \mathrm{Pb} \\
K=1830 \times P_{\mathrm{PV}}+1.60 \times 350 \times C_{\text {bat }}, & \text { for } \mathrm{Li}-\text { ion }
\end{array}
$$

The optimization then consists of finding the PV/battery combination with the lowest cost that fulfills the requirement of running out of power at less than the specified frequency.

\section{Results and Discussion}

Geospatial analysis has been applied to the models from Section 2 seeking to explain patterns of the PV mini-grid performance and its spatial expression in terms of geographical location. Results are presented for an area covering Africa and most of Southern and Central Asia.

\subsection{Calculation Set-Up}

All calculations were performed on an area bounded by the following coordinates:

- North: $40^{\circ} \mathrm{N}$

- $\quad$ South: $35^{\circ} \mathrm{S}$

- West: $20^{\circ} \mathrm{W}$

- $\quad$ East: $110^{\circ} \mathrm{E}$ 
The calculation was split into two geographical regions corresponding to the data from the two satellites [32,34], with a split at $40^{\circ}$ E. Subsequently, the two data sets were spliced together to produce the maps in the following sections.

In order to avoid excessive computing time, the spatial resolution was set to 6 arc-minutes, compared to the $3^{\prime}$ resolution of the solar radiation data.

The calculations were performed using hourly solar radiation and temperature data for a total of 3 years, covering the period 2009-2011.

\subsection{Spatial Analysis of PV Mini-Grid Performance for a Given PV Generator and Battery Size}

The performance of a PV mini-grid was calculated by running a total of four scenarios, using two battery types and two different consumption profiles. For these simulations, the size of the PV generator was set to a nominal power of $70 \mathrm{kWp}$, while the effective battery storage was set to $720 \mathrm{kWh}$. The total daily consumption was assumed to be $300 \mathrm{kWh} /$ day in all locations. The recommended low-charge cut-off point varies from different battery types, this means that the nominal capacity will not be the same for Li-ion and lead-acid batteries. We assume a $40 \%$ cut-off for lead-acid that corresponds to a nominal capacity of $1200 \mathrm{kWh}$, while for a Li-ion battery we assume a cut-off of $20 \%$ corresponding to a nominal battery size of $900 \mathrm{kWh}$.

\subsubsection{PV Mini-Grid Energy Production}

Figure 5 shows the average daily energy supplied by a PV mini-grid $(70 \mathrm{kWp})$ in the computational region, using lead-acid batteries and the consumption profile with high nighttime consumption pattern.

When averaged over a long period of time it is not possible for the PV mini-grid to produce more energy than what is consumed. This is because the energy not consumed would have to be stored in the battery, which is sized to contain a little over two days' worth of energy consumption. This is clearly seen from the map (Figure 5) where large areas show that PV mini-grid is sufficiently large to supply the daily specified consumption of $300 \mathrm{kWh} /$ day. This is the case in the areas shown in red in the map: desert areas of North Africa, the Arabian Peninsula, in Southwest Africa as well as eastern Iran and parts of Pakistan and Afghanistan.

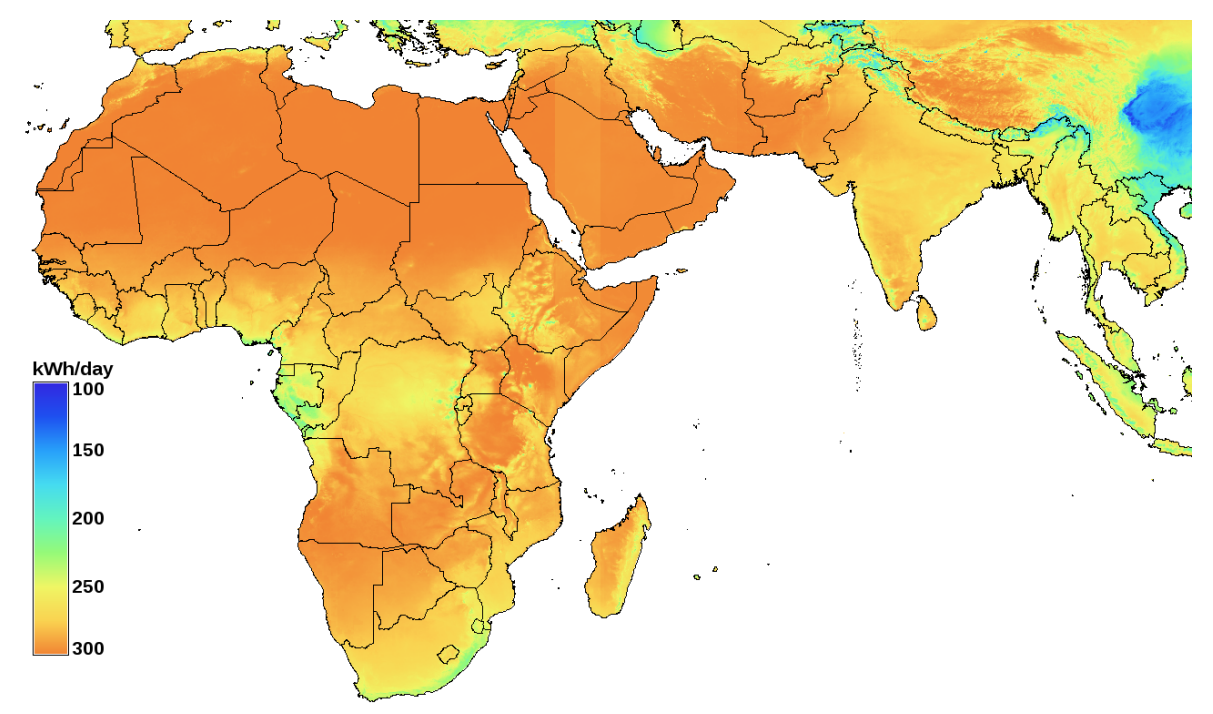

Figure 5. Average daily energy supply (kWh) by a PV mini-grid (70 kWp PV generator, $720 \mathrm{kWh}$ lead-acid battery). The total daily consumption assumed for the calculations is of $300 \mathrm{kWh} /$ day with a high nighttime consumption pattern.

In regions with more variable solar resource the average energy production per day is lower; the energy production is still around $275 \mathrm{kWh} /$ day in most of India and South-east Asia, dropping 
to about $225 \mathrm{kWh} /$ day in tropical West Africa, with the lowest values found in Southeast China where the energy production from a PV mini-grid of this size is only about half of the desired energy consumption. Clearly, in such areas a PV array of $70 \mathrm{kWp}$ is of insufficient size to supply the desired amount of electricity.

\subsubsection{PV Mini-Grid Power Interruptions}

Figure $6 a, b$ shows the percentage of days when the PV mini-grid (with lead-acid battery) runs out of energy for the two different consumption profiles. Mini-grid characteristics are the same as those used for Figure 5.

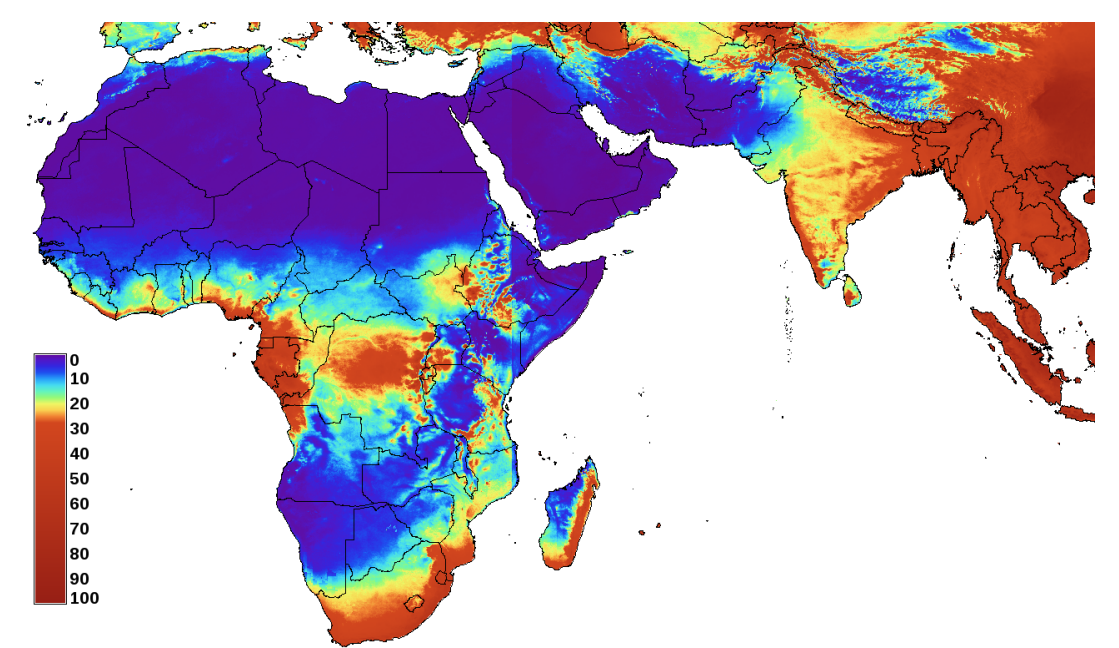

(a)

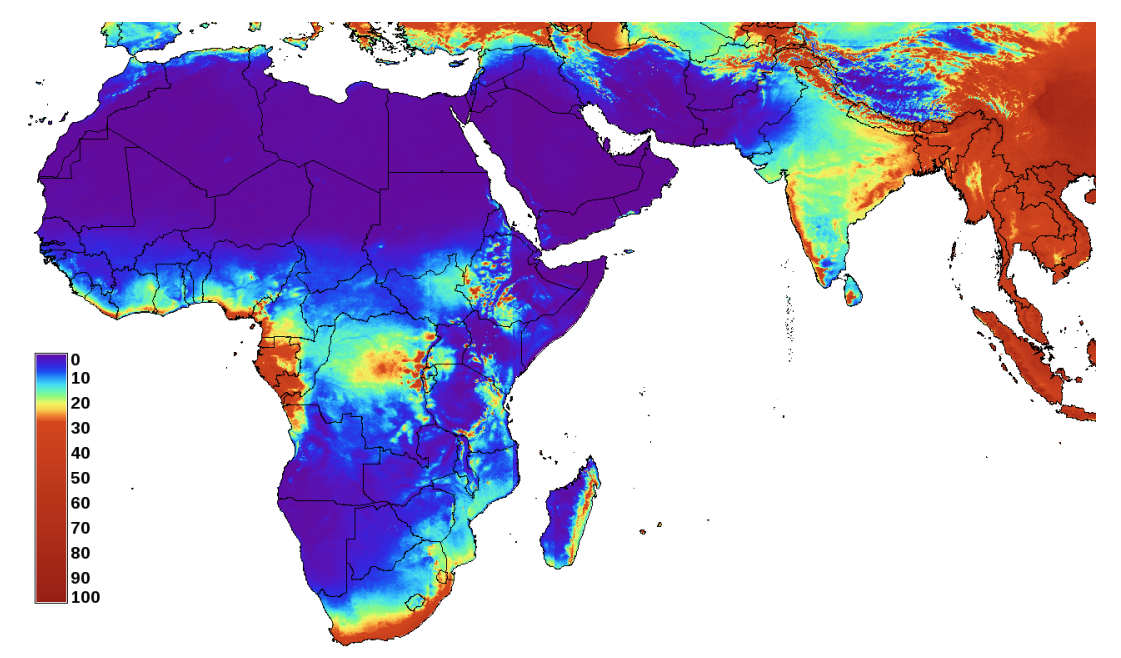

(b)

Figure 6. Percentage of days when the PV mini-grid (70 kWp PV, $720 \mathrm{kWh}$ lead-acid battery) runs out of energy for (a) high nighttime consumption and (b) low nighttime consumption.

These maps show that in desert areas the PV mini-grid will almost never run out of energy while in other areas the number of days with power interruptions will be significant. In most of India the mini-grid will run out of energy about $20 \%-25 \%$ of days with the high nighttime consumption profile and $15 \%-20 \%$ of days with the low nighttime consumption profile. These figures rise to $30 \%-40 \%$ in tropical West Africa and Southeast Asia and reach more than $80 \%$ of days in parts of China showing that in these areas the given mini-grid size will almost never be able to supply the specified amount of energy for a full 24-h period. 
There is a significant difference in the reliability of the PV mini-grids depending on the consumption profile. Figure 7 shows the difference between the two maps given in Figure 6 . The difference is shown as the absolute difference in frequency of power loss between the two load profiles. Again in some areas there is little difference while in other areas such as part of South Africa there are significantly more days with missing power for the high nighttime consumption case.

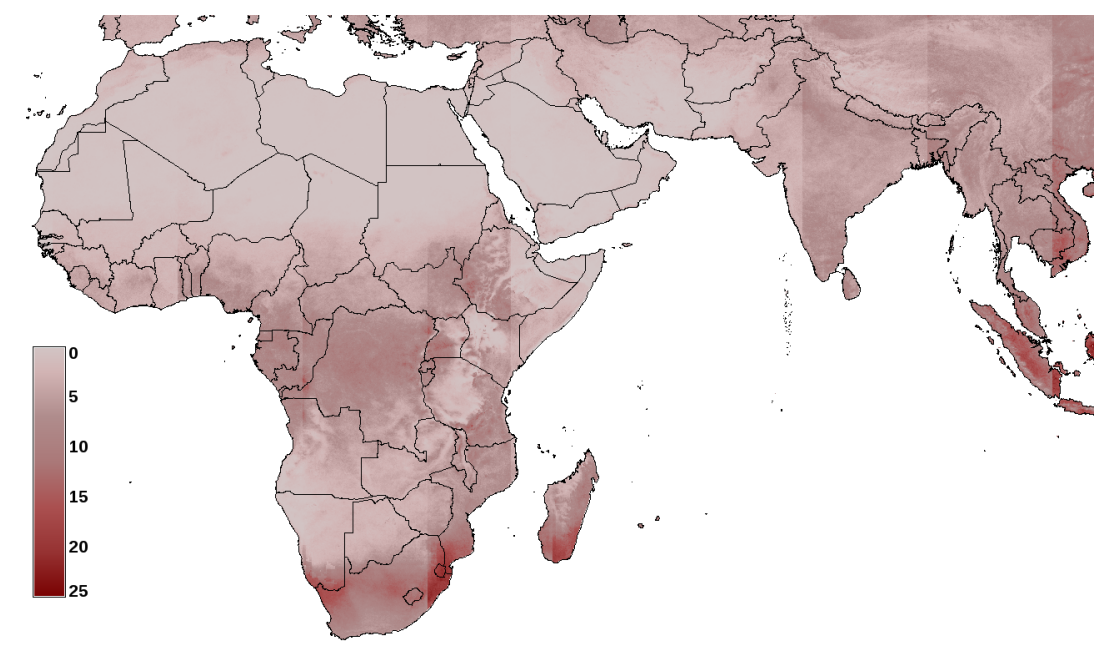

Figure 7. Difference in percentage of days with power loss between the high nighttime consumption and the low nighttime consumption. Mini-grid characteristics are the same as those used for Figure 5.

The "stripiness" in the map is caused by the fact that the consumption profile is shifted by one whole hour for every $15^{\circ}$ longitude as discussed in Section 2.4.2.

The calculation of PV mini-grid performance was also performed using Li-ion batteries as storage instead of lead-acid batteries. Figure 8 shows the difference in the percentage of days with missing energy when using lead-acid batteries instead of Li-ion batteries.

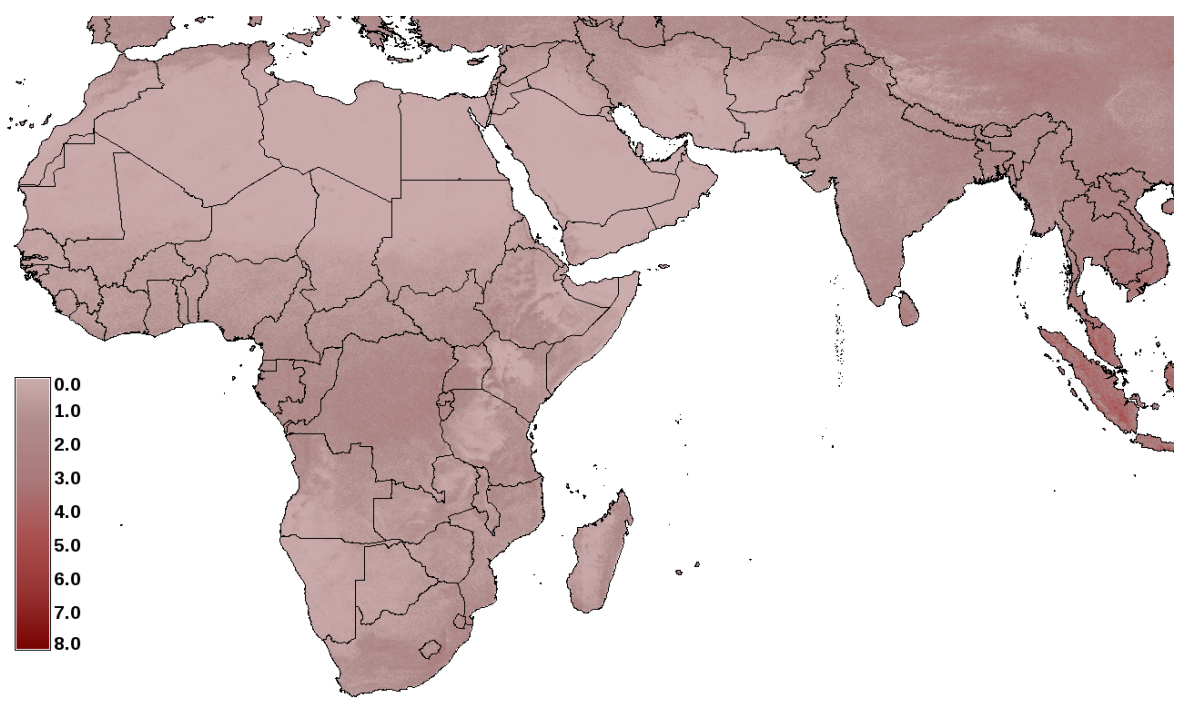

Figure 8. Difference in percentage of days with power loss when using lead-acid batteries compared to using Li-ion batteries with the same effective capacity, using the low night-time consumption profile. Note that the scale is different from that used in Figure 7. 
Again here, in some areas the mini-grid will have practically no days without energy with either technology while in other areas some difference is evident. The difference is not very large, with values ranging from 0 to $8 \%$ difference in days with missing energy, with the largest difference found in tropical East Asia. As noted earlier, the calculations use the same effective battery size. This means that the nominal size of the Li-ion batteries is only three-quarters of the nominal size of the lead-acid batteries. The difference in performance seen in Figure 8 is caused by the slightly lower internal losses in Li-ion batteries.

What is clear from this example is that the performance of a PV mini-grid will depend very strongly on the local climatic conditions. The obverse of this observation is of course that the same $\mathrm{PV} /$ battery combination will not be equally suitable everywhere.

\subsection{PV Mini-Grid Optimization: Balance between PV Array Size and Battery Capacity}

The PV mini-grid optimization consists of finding the PV/battery combination with the lowest cost that fulfills the requirement of running out of power at less than the specified frequency. The algorithm has been described in Section 2.5. In this section, we present the details of the simulations and some results.

\subsubsection{Calculation Set-Up}

The geographical region, time period and spatial resolution is the same as for the non-optimized calculation presented in Section 3.2. Also the PV and battery data used are identical. For these calculations, the reliability criterion for the PV mini-grid is that it should run out of energy on a maximum of $5 \%$ of days.

The PV mini-grid optimization calculation runs with a range of PV generator and battery sizes. For the calculations, we use the same desired consumption of $300 \mathrm{kWh}$ per day (this choice is arbitrary since the PV, battery, and consumption scale linearly in the model). For this consumption, the PV generator capacity is varied in 10 steps from $60 \mathrm{~kW}_{\mathrm{p}}$ to $180 \mathrm{~kW}_{\mathrm{p}}$, while the effective battery capacity has 10 steps from $200 \mathrm{kWh}$ to $560 \mathrm{kWh}$.

\subsubsection{Optimization Calculation Results}

The output of the optimization process are the maps of PV array and battery size for the chosen battery type, consumption pattern and level of reliability. Figure 9 shows the optimum PV generator and battery sizes for the simulation case with lead-acid batteries and high nighttime consumption. For some regions it was not possible to find any combination of PV array and battery size that satisfied the $5 \%$ power loss criterion within the limits given for the PV and battery size. These regions are shown without colour in the maps. These are generally areas with low overall insolation or in the northernmost part of the region where low solar radiation in winter makes it difficult to ensure high reliability of power delivery. Of course the optimization can be performed also for these regions by increasing the maximum PV and/or battery size used for the optimization.

Not surprisingly the general pattern follows that of the energy production for a constant mini-PV grid size shown in Figure 5. In areas where the constant PV mini-grid size is able to produce nearly all the energy that is required, a relatively small PV/battery system is sufficient to deliver energy with high reliability. In regions where the average energy supplied is lower, the PV/battery combination must be larger and the regions with lowest energy output are generally outside the area where it was possible to find an optimum PV/battery size within the limits set by the simulation.

Nevertheless there are also some important variation in the optimum PV/battery size which is not simply correlated with the average energy output for a fixed-size PV mini-grid. An example is shown in Table 1. Two different sites, one in Cameroon and one in India, have almost the same average energy output from the fixed-size system, and percentage of days with missing energy is also very similar. However, the site in India requires a PV size more than 50\% larger and battery size about 17\% higher than the site in Cameroon. This is related to the stronger seasonality in India where July and 
August typically have low solar irradiation. This leads to a higher probability of running out of energy unless the PV array is sized substantially larger.

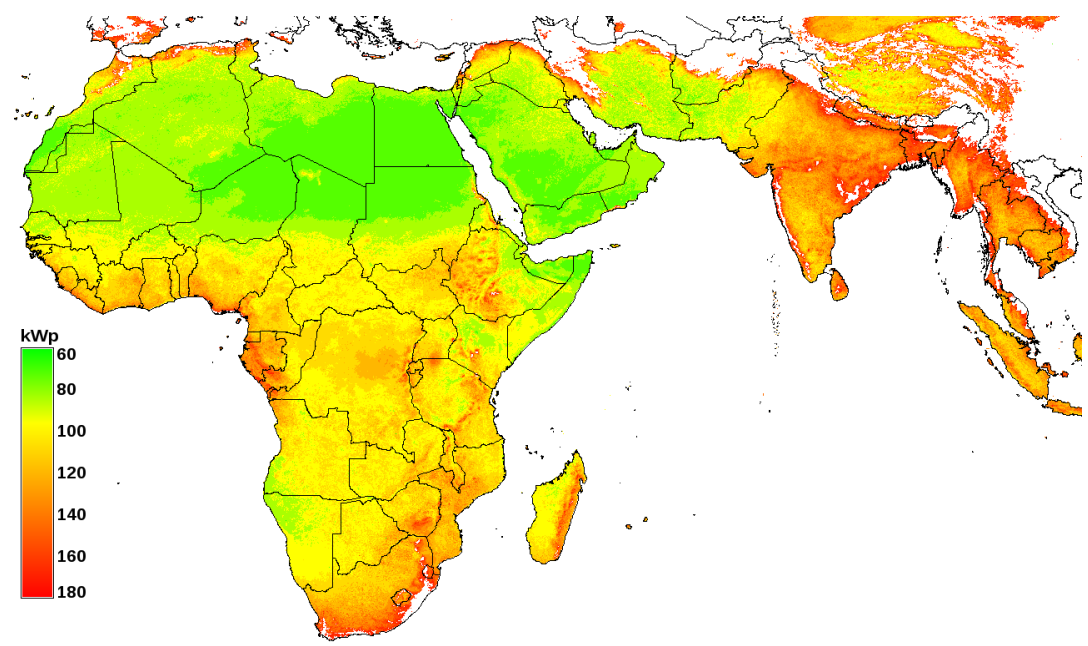

(a)

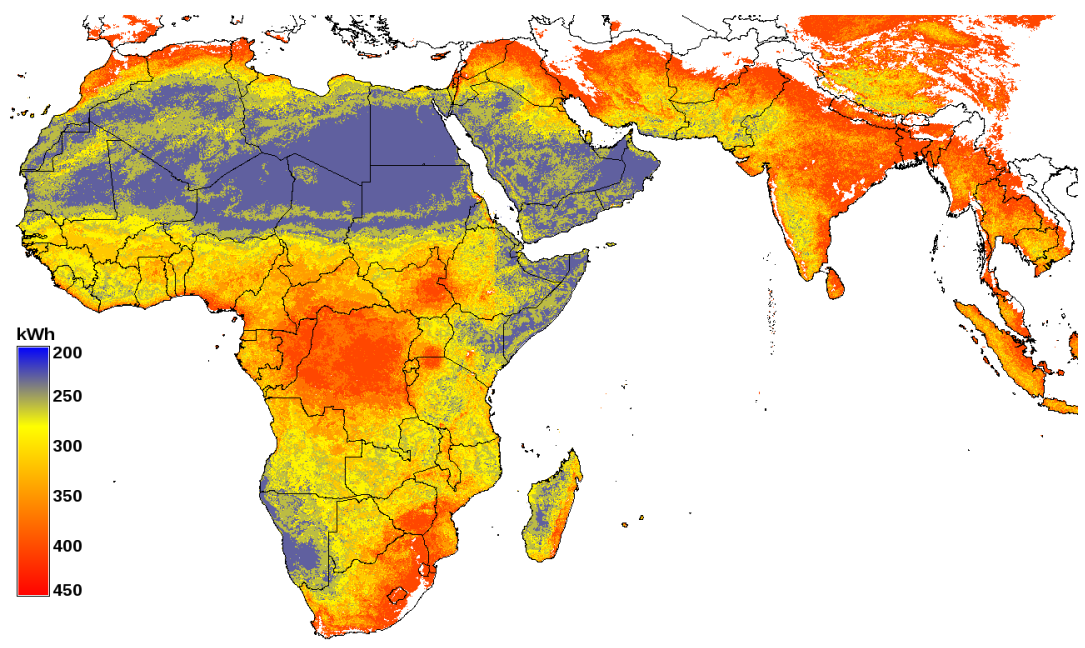

(b)

Figure 9. Optimum size of PV array (a) and optimum battery capacity (b) that ensures a frequency of power outage less than $5 \%$ of days. Areas shown in white require PV or battery size that are larger than the ones given by the limits used for the calculation. This calculation assumed the high nighttime consumption pattern and lead-acid batteries.

Table 1. Optimum PV and (effective) battery size for two sites which have similar average energy delivery from the constant PV/battery system size of Section 3.2.

\begin{tabular}{lcc}
\hline Sites & Cameroon & India \\
\hline Latitude & $2.65^{\circ} \mathrm{N}$ & $19.75^{\circ} \mathrm{N}$ \\
Longitude & $12.55^{\circ} \mathrm{E}$ & $83.95^{\circ} \mathrm{E}$ \\
Energy, non-optimized (kWh/day) & 257 & 258 \\
Missing, non-optimized (\%) & 29.5 & 33.8 \\
PV size, optimized $(\mathrm{kWp})$ & 108 & 168 \\
Battery size, optimized $(\mathrm{kWh})$ & 480 & 560 \\
\hline
\end{tabular}

Figure 10 shows the ratio of effective battery and PV generator size for the calculation shown in Figure 9 . This ratio varies by almost a factor four from about 2 to nearly $8 \mathrm{kWh} / \mathrm{kW}$. Here there is no 
obvious correlation with PV mini-grid size. Low values of the ratio (corresponding to a small battery for given PV size) are found both in very sunny areas of Namibia and more consistently cloudy areas like Gabon, while a high ratio is found both in Congo (relatively low irradiation) and parts of Iran with higher irradiation, but with higher winter/summer seasonality. For comparison Figure 10 also shows a map of the ratio of battery and PV size for the low nighttime consumption case with Li-ion batteries. For this case the ratio is generally lower (smaller battery for given PV size), never rising above 6. In areas with a stable sunny climate such as Egypt, the ratio is only about half as large, mainly due to the lower battery size needed to supply energy at night.

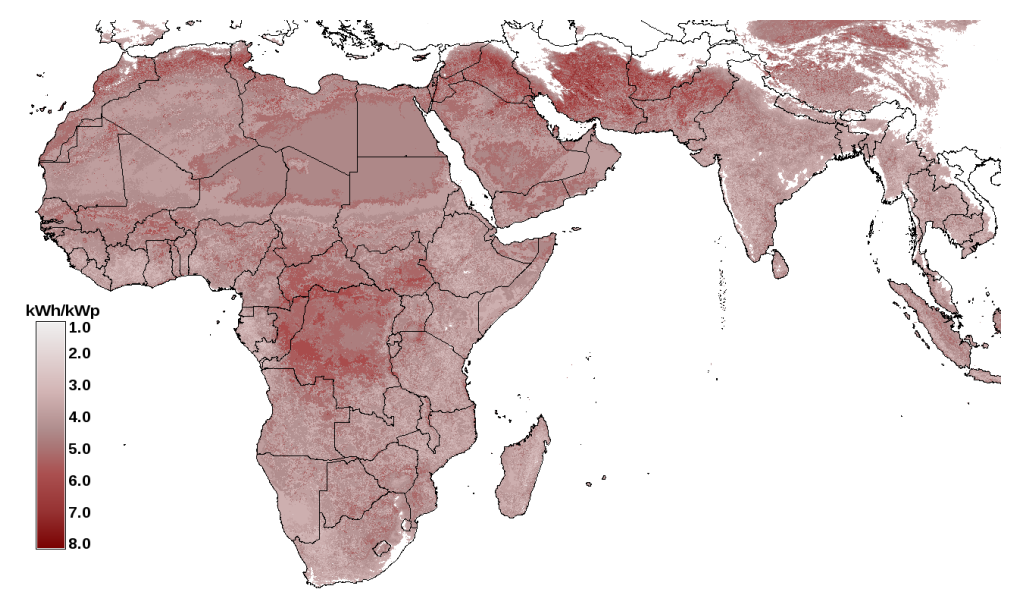

(a)

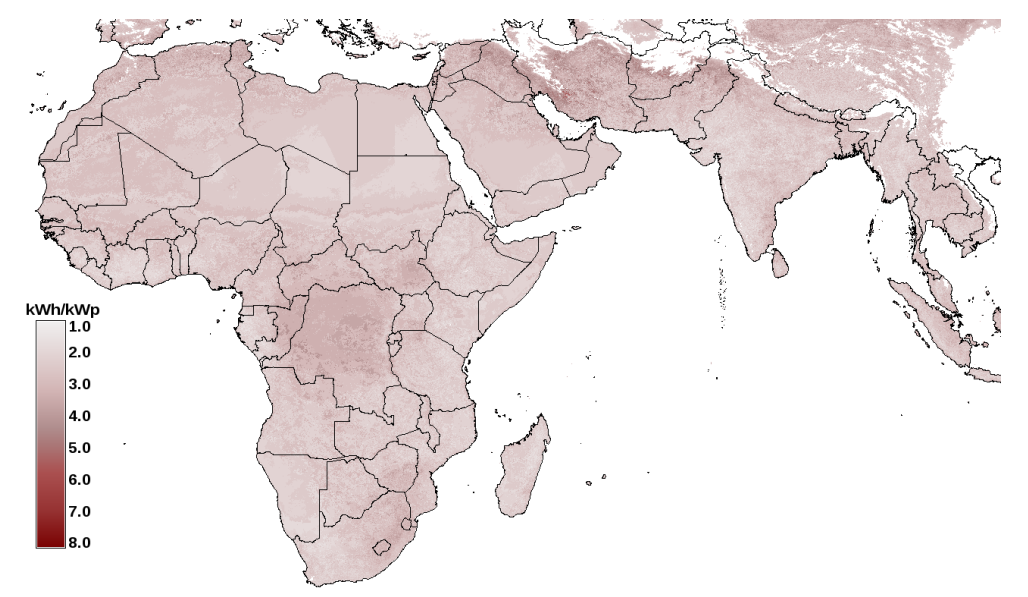

(b)

Figure 10. Ratio between optimum battery size (effective $\mathrm{kWh}$ ) and optimum PV array size $\left(\mathrm{kW}_{\mathrm{p}}\right)$. (a) Simulation with lead-acid batteries and high nighttime consumption (the simulation shown in Figure 9); (b) simulation with Li-ion batteries and low nighttime consumption.

The optimization calculations were performed for the same four scenarios as the constant size (non-optimized) calculation of Section 3.2: with either low or high nighttime consumption, and employing either lead-acid or Li-ion batteries.

The geographical variation in the differences between the calculations are somewhat less clear than in the maps shown up to now, so these maps will not be shown here (The raster maps are available in the supplemental material online [42]). Instead, we have calculated histograms of the differences in PV generator and battery sizes when comparing these scenarios:

- High nighttime versus low nighttime consumption for Lead-acid batteries

- Lead-acid batteries versus Li-ion batteries for the high nighttime consumption scenario 
Since the battery and PV sizes are in discrete values, the difference in size will also show only discrete values. Thus, we can calculate the total geographical area that exhibits a certain value in the difference in PV or battery size. The results of this calculation are shown in Figure 11.

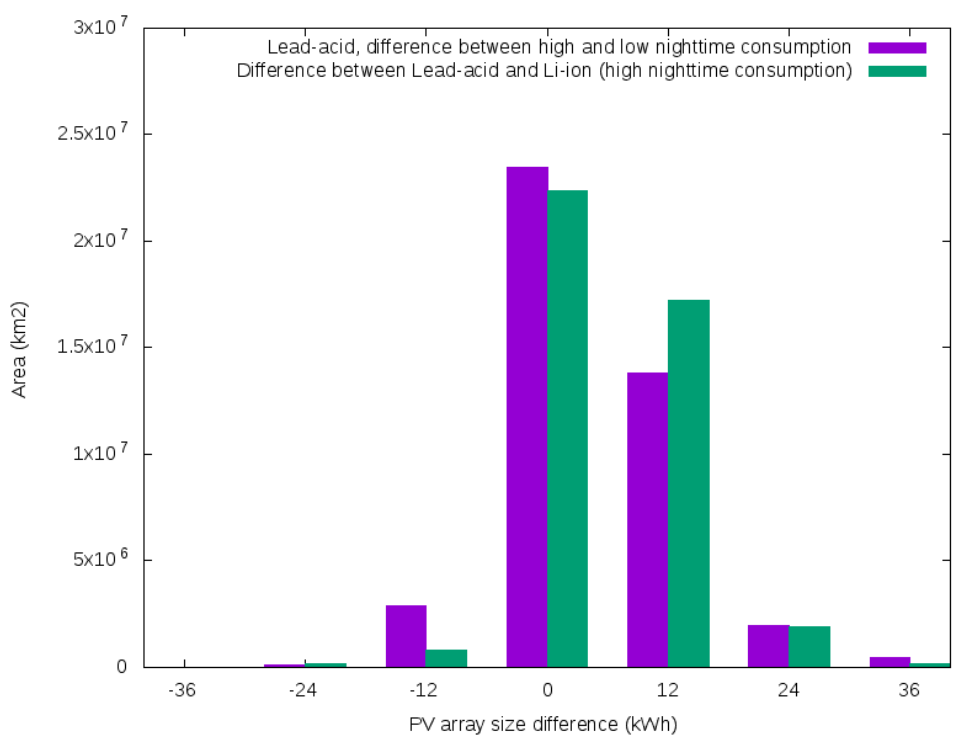

(a)

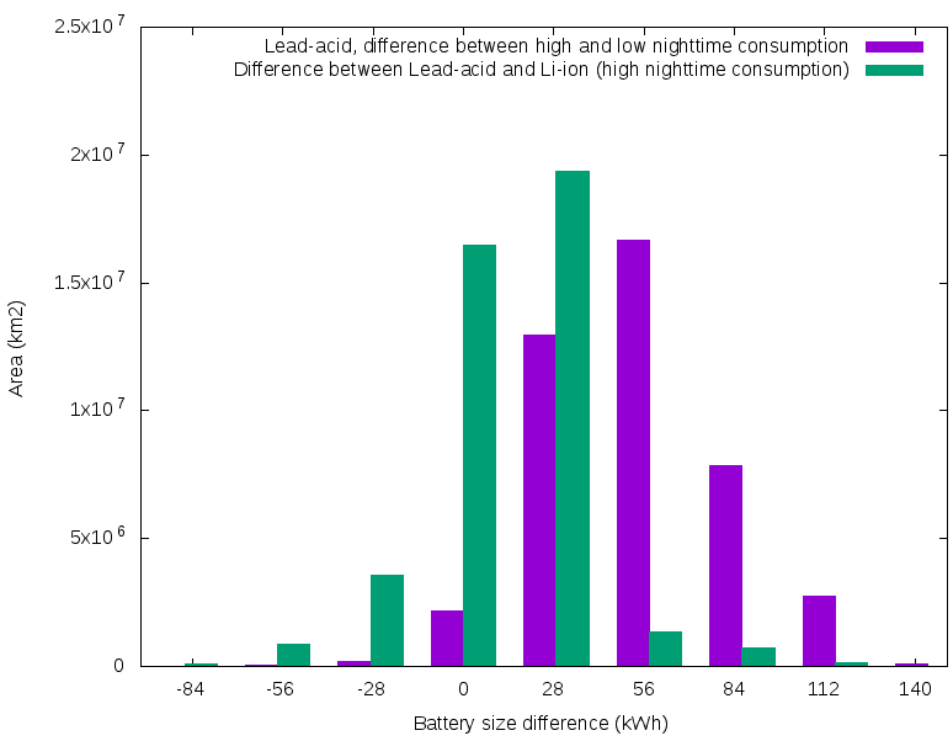

(b)

Figure 11. Histograms of the occurrence of difference in optimum system size when changing between high nighttime and low nighttime consumption (using Lead-acid batteries), and when changing battery technology from Li-ion to lead-acid (for the high nighttime consumption case) (a) Difference in PV generator size (kWp); (b) difference in effective battery size $(\mathrm{kWh})$.

For about $50 \%$ of the analysed territory, there is no difference in the PV array optimal size when changing consumption profile or battery type.

However, in most of the rest of the territory the PV array size increases somewhat when changing from low nighttime to high nighttime consumption or from Li-ion to lead-acid batteries. In about $7 \%$ of the area, the high nighttime consumption pattern actually requires a smaller PV generator. This is not so surprising since the optimum PV generator size tends to depend on the total energy required more than on the exact time when the energy is needed. 
The battery size is nearly always larger when increasing the share of nighttime consumption. The most common difference, $69 \%$ of the analysed territory, is in the range $25-50 \mathrm{kWh}$ larger battery capacity (for a daily consumtpion of $300 \mathrm{kWh}$ ). Conversely, there is generally only a smaller difference in battery size when changing from Li-ion to lead-acid batteries, with large geographical areas (39\%) having no difference and the most common difference $(45 \%)$ being a small change of about $30 \mathrm{kWh}$. The difference in battery size in the two scenarios is partially due to the fact that Li-ion batteries have lower charge/discharge cycle losses. However, the optimization was performed by finding the lowest mini-grid cost. Since lead-acid batteries are somewhat cheaper than Li-ion in the chosen case study, there is also the possibility that the optimization will offset a smaller Li-ion battery with a larger PV array to reach the required threshold frequency of power loss.

\subsubsection{Electricity Production Costs}

Using the assumptions for the installation and replacement costs given in Equation (9), it is possible to calculate the cost of the energy produced by the PV mini-grid system.

For the calculation we have used the scenario with low night-time consumption and Li-ion batteries. The total cost of the PV mini-grid system consists of the system cost given by Equation (9) together with operation and maintenance (O\&M) costs. For O\&M we have assumed a value of $2 \%$ per year of the cost of the PV array and balance-of-system components. Maintenance of the batteries is assumed to be covered by the periodic replacement. The cost of the electricity is then found by dividing the total system cost by the energy produced over the 20-year lifetime of the system.

The result of the cost calculation is shown in Figure 12. It should be noted that this cost only covers the construction and maintenance of the PV/battery system. Costs incurred for the local electricity grid are not included.

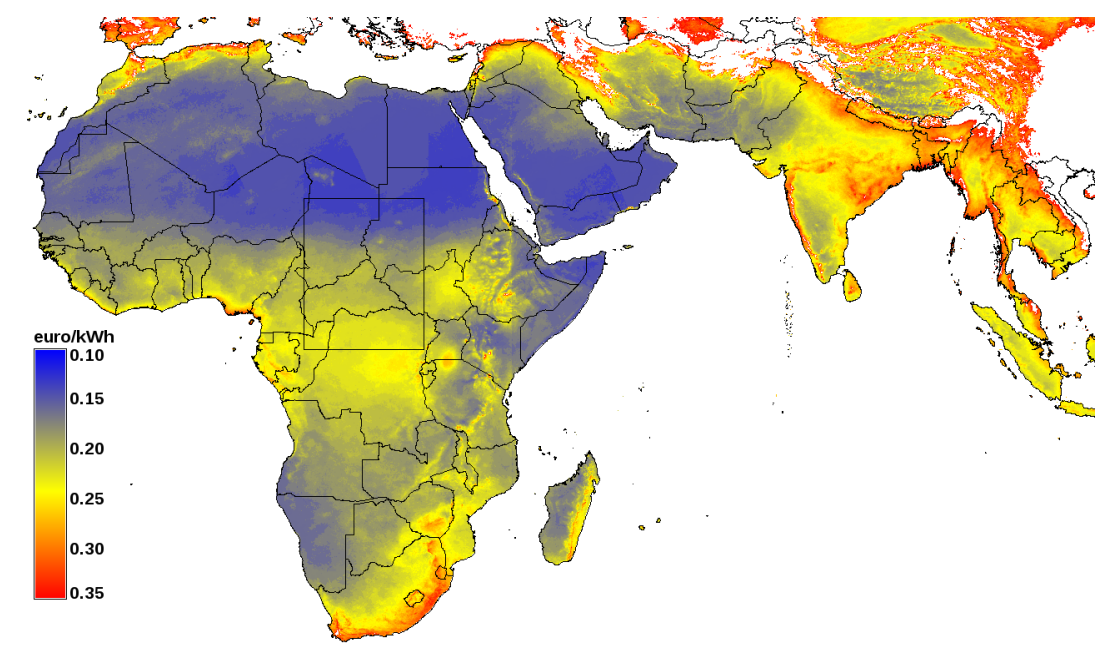

Figure 12. Cost of the electricity produced by a PV mini-grid system with Li-ion batteries serving a load with low night-time consumption. The cost is given in $€ / \mathrm{kWh}$ of electricity produced. The black rectangle in Central Africa outlines the region used for the calculation shown in Figure 13 below.

\subsubsection{Effect of Varying the Power Loss Frequency}

The optimization calculations performed so far have all used the same criterion for energy delivery reliability: the system must not run out of power on more than $5 \%$ of days. This criterion was not chosen quite arbitrarily; many of the countries that have a large share of the population without electricity access also have problems with blackouts in the areas covered by the electricity grid. In view of this the $5 \%$ seems a reasonable threshold that should provide a quality of service at least as good as that of the national grid. However, it might be possible to get cost savings from relaxing this criterion. 
To investigate this, we chose a region in Central Africa ranging in latitude from $0^{\circ} \mathrm{N}$ to $18^{\circ} \mathrm{N}$ and from $15^{\circ} \mathrm{E}$ to $30^{\circ} \mathrm{E}$. (outline shown in Figure 12). This region was chosen because it contains a wide range of climates from desert (southern Chad) to tropical humid (northern DRC). In this region we calculated the optimal system with Li-ion batteries and the low night-time consumption pattern for the two power loss thresholds of $10 \%$ and $20 \%$.

The results are shown in Figure 13. The results are shown as the electricity cost savings when using a threshold value of $10 \%$ or $20 \%$, relative to the base scenario with a threshold of $5 \%$.

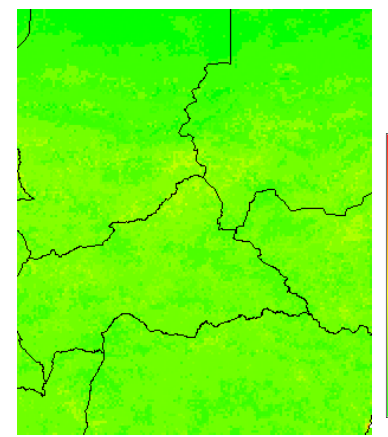

(a)

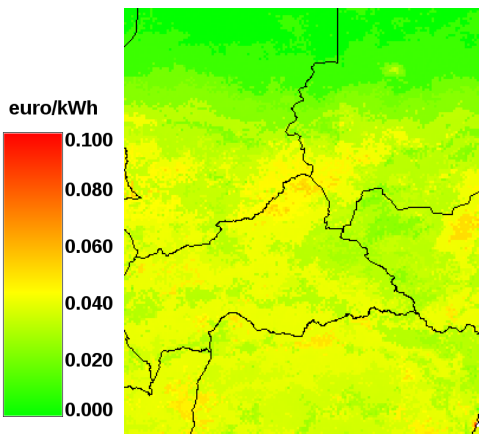

(b)

Figure 13. Electricity cost savings when choosing a reliability threshold of (a) $10 \%$ of days or (b) $20 \%$ of days with power loss, compared to the base scenario of $5 \%$ of power loss. Calculations are performed for an area in Central Africa ranging in latitude from $0^{\circ} \mathrm{N}$ to $18^{\circ} \mathrm{N}$ and from $15^{\circ} \mathrm{E}$ to $30^{\circ} \mathrm{E}$. The values are given in $€ / \mathrm{kWh}$.

\section{Conclusions}

We have presented a GIS-based tool for estimating the performance of PV mini-grid systems with battery storage over large geographical areas. The tool makes use of multi-year hourly time series of solar radiation and temperature to model the PV power production, and makes a detailed calculation of the battery state and losses. The results are maps of energy production, unfulfilled demand, and the reliability of the electricity production in terms of the fraction of days with power cuts due to missing energy in the system. Calculations are presented for an area covering Africa and most of Southern and Central Asia.

The tool may be useful for governments, local authorities and non-governmental organizations to investigate the suitability of PV mini-grids for electrification of regions where access to electricity is lacking. In this way it is possible to identify areas where PV mini-grids are most suitable. Of course, a more detailed investigation should then be carried out for a specific site, including the cost of wiring up the local area, something that is not considered in the presented methodology.

In order to highlight the variation in performance and reliability of the PV mini-grid size, the geospatial analysis has been performed on a constant PV mini-grid size (not-optimized for each location). The results are maps that depicts the variations in energy production at large areas level showing how the daily energy production of the same PV mini-grid drops to less than half by changing the location (i.e., from $300 \mathrm{kWh}$ in Pakistan to $120 \mathrm{kWh}$ in Southeast China). These results show the need to correctly size the PV mini-grid to avoiding over- or undersizing the system for the given geographical conditions. We have therefore also calculated the optimum size of PV array power and battery capacity that can deliver energy with a specified level of reliability at the lowest possible cost. The general pattern is similar to the constant size mini-grid analysis in that PV mini-grid performance depends strongly on the local climatic conditions. However, the results show an important variation that is not correlated with the constant size analysis: areas with strong seasonability require larger PV and battery size (compared to a location with same average output but lower sesonal variation) in order to avoid to run out of energy in the months where the solar irradiation is lowest. 
The geospatial tool makes it possible to analyse the variability of unfulfilled demand and reliability of the electricity production when the energy consumption patterns change, or when changing the energy storage type from lead acid batteries to Li-ion batteries. Changing storage technology does not cause a large difference in performance, and the difference is mostly caused by lower internal losses in Li-ion batteries. In the case of changing consumption patterns (having same amount of daily energy consumed but differently distributed along the day) the variation is more prominent with some areas showing significatly more days with power cuts when increasing consumption share at night.

The visual representation of the results may be useful for governments, local authorities and non-governmental organizations to investigate the suitability of PV mini-grids for electrification of regions where access to electricity is lacking. In this way it is possible to identify areas where PV mini-grids are most suitable and identify the most appropriate sizing for rural electrification programmes. On the other hand, a limitation of the study is the fact that the geospatial input cannot consider relevant parameters that determine the optimum (and the feasibility) of PV mini-grids such as socio-economic parameters because of the broad spatial scope and large differences between the countries. A more detailed investigation should then be carried out for a specific site, including local specific characterisitics, something that is not considered in the presented methodology.

There is scope for further optimization of the methodology in a number of areas:

- In our model the consumption profile does not vary from day to day or over the seasons. In order to make a comparative analysis at continental level, the PV mini-grid has been designed to minimize the number of cases of loss of power but has not been tailored by location. Therefore it is likely that in some regions the PV mini-grids are oversized or underdimensioned. A step forward to improve the model would be to take in consideration if there are marked seasonal variation, for instance increased use of lighting during winter or increased use of refrigeration during the hottest months, the question arises how this correlates with PV energy production.

- The results shown in the present paper have only considered crystalline silicon modules for the PV array. The analysis could be extended to other PV technologies, such as CIS/CIGS or CdTe. In addition, there are effects such as wind cooling of the PV modules that could be included in the performance calculation.

- Finally, a further optimization that could be included is to find also the optimum inclination angle of the PV modules that will guarantee the required reliability at minimum cost. However, that would require a different approach on the method by introducing an extra independent variable (inclination angle). It is not clear if the present raster-based approach would still be feasible, or if it would necessitate a different organization of the climatic data where the calculation would be performed in a pixel-wise manner where more detailed optimization algorithms can be applied.

Acknowledgments: This study was funded entirely by the Host Institution of the authors: European Commisison Joint Research Centre.

Author Contributions: The contributions of the authors to this paper are as follows: Thomas Huld wrote the model software and performed the calculations for the study. Magda Moner-Girona contributed to the design of the socio-economic calculations and the description of the policy background. Akos Kriston performed the measurements of battery performance and wrote the description of the battery performance data.

Conflicts of Interest: The authors declare no conflict of interest.

\section{References}

1. International Energy Agency (IEA). World Energy Outlook 2015; IEA: Paris, France, 2015; Chapter 2.

2. Organisation for Economic Co-operation and Development/International Energy Agency. Energy Poverty: How to Make Modern Energy Access Universal? Number September; OECD/IEA: Paris, France, 2010; p. 52.

3. Bazilian, M.; Nussbaumer, P.; Rogner, H.H.; Brew-Hammond, A.; Foster, V.; Pachauri, S.; Williams, E.; Howells, M.; Niyongabo, P.; Musaba, L.; et al. Energy access scenarios to 2030 for the power sector in sub-Saharan Africa. Util. Policy 2012, 20, 1-16. 
4. Pachauri, S.; van Ruijven, B.J.; Nagai, Y.; Riahi, K.; van Vuuren, D.P.; Brew-Hammond, A.; Nakicenovic, N. Pathways to achieve universal household access to modern energy by 2030. Environ. Res. Lett. 2013, 8, 8.

5. Sustainable Energy For All (SE4All). Global Tracking Framework; Technical Report; SE4All: Washington, DC, USA, 2012.

6. Bhattacharyya, S.C. Rural Electrification Through Decentralised Off-grid Systems in Developing Countries; Springer: London, UK, 2013.

7. Progress Toward Sustainable Energy; Global Tracking Framework 2015 Key Findings; Technical report; SE4All: Washington, DC, USA, 2015.

8. JRC-European Commission. RE2nAF, Off Grid Options for Rural Africa; JRC-European Commission: Ispra, Italy. Available online: http:/ / re.jrc.ec.europa.eu/re2naf.html (accessed on 8 February 2017).

9. Szabó, S.; Bódis, K.; Huld, T.; Moner-Girona, M. Energy solutions in rural Africa: Mapping electrification costs of distributed solar and diesel generation versus grid extension. Environ. Res. Lett. 2011, 6, doi:10.1088/1748-9326/6/3/034002.

10. Szabó, S.; Bódis, K.; Huld, T.; Moner-Girona, M. Sustainable energy planning: Leapfrogging the energy poverty gap in Africa. Renew. Sustain. Energy Rev. 2013, 28, 500-509.

11. Bhattacharyya, S.C.; Palit, D.; Kishore, V.V.N.; Boait, P.J.; Mohanty, P.; Muneer, T.; Mishra, A.; Sarangi, G.K.; Sharma, K.R.; Palit, D.; et al. Mini-Grids for Rural Electrification of Developing Countries; Springer: London, UK, 2014.

12. Bhattacharyya, S.C.; Palit, D. Mini-grid based off-grid electrification to enhance electricity access in developing countries: What policies may be required? Energy Policy 2016, 94, 166-178.

13. Cader, C.; Bertheau, P.; Blechinger, P.; Huyskens, H.; Breyer, C. Global cost advantages of autonomous solar-battery-diesel systems compared to diesel-only systems. Energy Sustain. Dev. 2016, 31, 14-23.

14. Parshall, L.; Pillai, D.; Mohan, S.; Sanoh, A.; Modi, V. National electricity planning in settings with low pre-existing grid coverage: Development of a spatial model and case study of Kenya. Energy Policy 2009, 37, 2395-2410.

15. Moner-Girona, M.; Bódis, K.; Huld, T.; Kougias, I.; Szabó, S. Universal access to electricity in Burkina Faso: Scaling-up renewable energy technologies. Environ. Res. Lett. 2016, 11, 084010.

16. Ohiare, S. Expanding electricity access to all in Nigeria: A spatial planning and cost analysis. Energy Sustain. Soc. 2015, 5, 1-18.

17. Mentis, D.; Welsch, M.; Fuso Nerini, F.; Broad, O.; Howells, M.; Bazilian, M.; Rogner, H. A GIS-based approach for electrification planning-A case study on Nigeria. Energy Sustain. Dev. 2015, 29, 142-150.

18. Kemausuor, F.; Adkins, E.; Adu-Poku, I.; Brew-Hammond, A.; Modi, V. Electrification planning using network planner tool: The case of Ghana. Energy Sustain. Dev. 2014, 19, 92-101.

19. United Nations Development Programme (UNDP). Sustainable Development Goals; UNDP: New York, NY, USA, 2016.

20. Energy Sector Management Assistance Program; Sustainable Energy for All. Beyond Connections. Energy Access Redefined; The International Bank for Reconstruction And Development/The World Bank Group: Washington, DC, USA, 2015.

21. Lambert, T.; Gilman, P.; Lilienthal, P. Micropower System Modeling with Homer. In Integration of Alternative Sources of Energy; John Wiley \& Sons, Inc.: Hoboken, NJ, USA, 2006; pp. 379-418.

22. HOMER Energy. HOMER-Hybrid Optimization of Multiple Energy Resources; HOMER Energy: Boulder, CO, USA, 2016.

23. RETScreen. RETScreen Clean Energy Management Software. 2016. Available online: http://www.nrcan.gc. ca/energy/software-tools/7465 (accessed on 8 February 2017).

24. Nagaura, T.; Tozawa, K. Lithium ion recargeable battery. Prog. Batter. Sol. Cells 1990, 9, $209-217$.

25. Lithium-Ion Batteries, Science and Technologies; Yoshio, M., Brodd, R.J., Kozawa, A., Eds.; Springer: New York, NY, USA, 2009.

26. Nitta, N.; Wu, F.; Lee, J.T.; Yushin, G. Li-ion battery materials: Present and future. Mater. Today 2015, 18, 252-264.

27. Nykvist, B.; Nilsson, M. Rapidly falling costs of battery packs for electric vehicles. Nat. Clim. Chang. 2015, 5, 329-332.

28. Become Competitive in the Global Battery Sector to Drive E-Mobility Forward; Technical Report; European Commission: Brussels, Belgium; Luxembourg, 2016. 
29. Muneer, T. Solar radiation model for Europe. Build. Serv. Eng. Res. Technol. 1990, 4, 153-163.

30. Š́ri, M.; Hofierka, J. A new GIS-based solar radiation model and its application to photovoltaic assessments. Trans. GIS 2004, 8, 175-190.

31. Martin, N.; Ruiz, J. Calculation of the PV modules angular losses under field conditions by means of an analytical model. Sol. Energy Mater. Sol. Cells 2001, 70, 25-38.

32. Müller, R.; Behrendt, T.; Hammer, A.; Kemper, A. A new algorithm for the satellite-based retrieval of solar surface irradiance in spectral bands. Remote Sens. 2012, 4, 622-647.

33. Posselt, R.; Mueller, R.; Trentmann, J.; Stockli, R.; Liniger, M. A surface radiation climatology across two Meteosat satellite generations. Remote Sens. Environ. 2014, 142, 103-110.

34. Gracia Amillo, A.; Huld, T.; Müller, R. A new database of global and direct solar radiation using the eastern Meteosat satellite, models and validation. Remote Sens. 2014, 6, 8165-8189.

35. Huld, T.A.; Friesen, G.; Skoczek, A.; Kenny, R.A.; Sample, T.; Field, M.; Dunlop, E.D. A power-rating model for crystalline silicon PV modules. Sol. Energy Mater. Sol. Cells 2011, 95, 3359-3369.

36. Huld, T.; Gracia Amillo, A. Estimating PV module performance over large geographical regions: The role of irradiance, air temperature, wind speed and solar spectrum. Energies 2015, 8, 5159-5181.

37. Huld, T.; Gottschalg, R.; Beyer, H.; Topič, M. Mapping the performance of PV modules, effects of module type and data averaging. Sol. Energy 2010, 84, 324-338.

38. Gracia Amillo, A.; Huld, T.; Vourlioti, P.; Müller, R.; Norton, M. Application of satellite-based spectrally resolved solar radiation data to PV performance studies. Energies 2015, 8, 3455-3488.

39. Dee, D.P.; Uppala, S.M.; Simmons, A.J.; Berrisford, P.; Poli, P.; Kobayashi, S.; Andrae, U.; Balmaseda, M.A.; Balsamo, G.; Bauer, P.; et al. The ERA-Interim reanalysis: Configuration and performance of the data assimilation system. Q. J. R. Meteorol. Soc. 2011, 137, 553-597.

40. Muñoz, J.; Narvarte, L.; Lorenzo, E. Experience with PV-diesel hybrid village power systems in Southern Morocco. Prog. Photovolt. Res. Appl. 2007, 15, 529-539.

41. Nordin, N.D.; Rahman, H.A. A novel optimization method for designing stand alone photovoltaic system. Renew. Energy 2016, 89, 706-715.

42. Huld, T.; Moner Girona, M.; Kriston, A. Supplementary Material for the Present Paper. Available online: http:/ / re.jrc.ec.europa.eu/supplementary/offgrid_mapping/index.html (accessed on 8 February 2017).

(C) 2017 by the authors; licensee MDPI, Basel, Switzerland. This article is an open access article distributed under the terms and conditions of the Creative Commons Attribution (CC BY) license (http:/ / creativecommons.org/licenses/by/4.0/). 